exam questions that cover these visual aids (e.g., identifying a type of object from a slide)?

C.D. Keyes: Yes, we occasionally do show slides, asking the students to recognize the object, its type, its role in the universe, etc. It can be done on the multiple choice system, even in large classes, but it does require special preparations (starting the slide show at the beginning of the exam; having different questions on different versions of the test to prevent cheating.)

\title{
THE PAPERLESS ASTRONOMY CLASSROOM
}

James C. LoPresto

Observatory, Edinboro University, Edinboro, Pennsylvania 16444, U.S.A.

The "Paperless Astronomy Classroom" was instituted at Edinboro University of Pennsylvania in the fall semester of the 1985-1986 academic year.

The goal of this endeavor was to teach an elementary and some advanced astronomy courses "on line" with the use of multiple terminals supported by a Digital VAX 11/785. Currently the system used is a clustered VAX system using two VAX 11/785's and one VAX 8550 .

The procedure of the "paperless classroom" eliminates the need for the transfer of paper between professor and students (homework, exams, supplementary handouts) in the first phase and eliminates the need for a textbook in the second phase.

An equally important goal is to provide additional enhancement for the student that may not be convenient or easily available from a textbook and the traditional classroom. Such an enhancement is series of large data bases, some of which can be the small data bases that traditionally appear in the appendices of textbooks. Another example might be a data base of graphs and charts (e.g., H-R diagrams, periodic table, abundance tables and graphs, binding energy curves, etc.).

The advantages to such an approach are many: The system

- is less expensive for the student.

- is less expensive for the college or university (paper costs).

- gives students access to enormous data bases.

- allows students to take instant tutoring lessons on a chapter-by-chapter basis or on a topical or subject basis.

- gives students access to powerful calculation capabilities.

- allows the student to interact on-line by changing parameters of a calculation and seeing the instantaneous changes in the results, e.g., change the sum of 
the masses or individual masses in a binary star system and watch the effect on the relative orbital sizes or change the relative positions, the masses and watch the orbits change shape.

- gives the students access to powerful graphics and allows the student to inspect, change, and make graphs.

- to varying degrees depending on the presentation, makes the student computer conversant (a valuable asset in today's society).

The paperless astronomy classroom is available in four formats, Digital VAX VMS, IBM PC MS-DOS, Macintosh Hypercard, and the traditional hard copy. In the material that follows, "VAX/VMS files" means VAX/VMS, IBM PC MS-DOS, and Macintosh Hypercard cards.

Material that can be considered either optional or supplementary or, most importantly, of an enrichment nature will be presented with the use of "VAX/VMS files," tutoring lessons, menu-driven programs, and graphics (both interactive and non-interactive). The tutoring lessons will emphasize the subject material in the hard-copy presentation. Additional tutoring lessons will be arranged in a topical fashion that will not follow the order of presentation in this "hard copy" or any textbook.

Another option is to have the "hard copy" available on magnetic tape, for subsequent placement on a system disk for electronic access along with the rest of the paperless classroom. Furthermore, as indicated above, this can be done in both the IBM PC version and the Macintosh Hypercard version.

In my opinion, students respond very positively to such a method of presentation. The reasons for this are perhaps many, but include the novelty compared to most courses they take. Further, the idea that instantaneously calling up data or information has an element of fun, power, and adventure associated with it. 


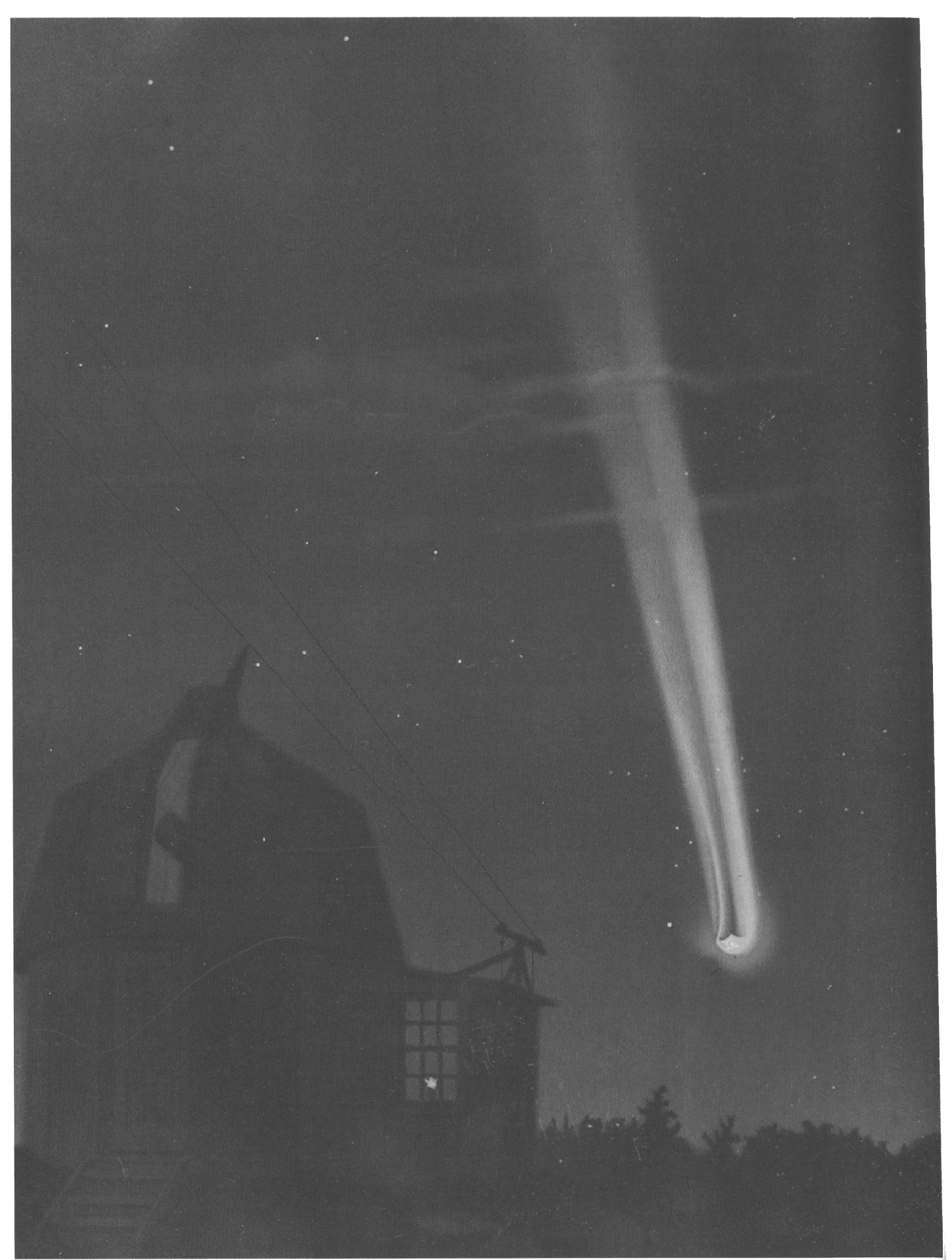

The Great Comet of 1881, by Etienne Léopold Trouvelot. Sawyer Library, Williams College. Further information on page 432. 